\title{
Le goût du lecteur à la fin du Moyen Âge, études réunies par Danielle Bohler
}

\section{Paola Cifarelli}

\section{(2) OpenEdition}

\section{Journals}

Édition électronique

URL : http://journals.openedition.org/studifrancesi/9438

DOI : 10.4000/studifrancesi.9438

ISSN : 2427-5856

Éditeur

Rosenberg \& Sellier

\section{Édition imprimée}

Date de publication : 1 décembre 2007

Pagination : 628-629

ISSN : 0039-2944

\section{Référence électronique}

Paola Cifarelli, « Le goût du lecteur à la fin du Moyen Âge, études réunies par Danielle Bohler », Studi

Francesi [En ligne], 153 (LI | III) | 2007, mis en ligne le 30 novembre 2015, consulté le 13 janvier 2021.

URL : http://journals.openedition.org/studifrancesi/9438; DOI : https://doi.org/10.4000/studifrancesi. 9438

Ce document a été généré automatiquement le 13 janvier 2021.

\section{(c) $($ ) $\odot$ (8)}

Studi Francesi è distribuita con Licenza Creative Commons Attribuzione - Non commerciale - Non opere derivate 4.0 Internazionale. 


\title{
Le goût du lecteur à la fin du Moyen Âge, études réunies par Danielle Bohler
}

\author{
Paola Cifarelli
}

\section{RÉFÉRENCE}

Le goût du lecteur à la fin du Moyen Âge, études réunies par Danielle BOHLER, Paris, Le Léopard d'Or, 2006 («Cahiers du Léopard d'Or», 11).

1 Dans ce volume se trouvent réunies dix-neuf contributions, organisées selon cinq noyaux thématiques; nous rendons compte ci-dessous des travaux concernant le domaine français.

2 Après l'introduction par D. Bohler, qui synthétise les enjeux de ce sujet interdisciplinaire et dynamique, la première section s'ouvre par l'étude de Jacqueline CERQUIGLINI-TOULET (La scène de lecture dans l'œuvre, pp. 13-26), qui porte sur la fonction remplie par les scènes de lecture destinées à susciter l'amour comme dans Yvain de Chrétien de Troyes, Durmart le Galois ou l'Espinette Amoureuse de Froissart ou bien évoquant un auteur dans l'acte d'écrire; c'est le cas du Livre de la Cité des Dames ou du Pèlerinage de la vie humaine de Guillaume de Digulleville. L'A. s'interroge donc sur les informations que l'on peut tirer à propos du gout des lecteurs, tel qu'il est évoqué dans ces ouvrages.

3 Florence воUснЕт (Pour une poétique du lecteur: le témoignage de quelques cuvres aux XIV et XV siècles, pp. 27-45) analyse les modalités d'inscription du lecteur dans le Dit de Franc Gontier de Philippe de Vitry, le Breviaire des Nobles d'Alain Chartier, le Livre du Chevalier Errant et plusieurs autres ouvrages comportant la lecture de recueils ou de morceaux choisis; elle s'interroge également à propos du rapport narrateur-lecteur tel qu'il ressort des formules d'adresse destinées à celui-ci ou des jeux graphiques et programmes iconographiques visant à établir un contact oculaire entre lecteur et texte. 
Jane H.M. TAYLOR (La mise en mélange au $\mathrm{XV}^{e}$ siècle: feuilleter le 'Jardin de Plaisance', pp. 47-63) met en évidence la stratégie éditoriale qui se cache derrière le célèbre florilège publié par Antoine Vérard vers 1501; en particulier, l'A. s'interroge à propos des procédés d'homogénéisation des différentes pièces, qui résultent en la création d'une «anthologie romancée» (p. 57).

5 Michel Pastoureau (Jouer aux chevaliers de la Table Ronde à la fin du Moyen Âge, pp. 65-81) porte un regard à la fois historique et sociologique sur les anthroponymes issus de personnages des romans arthuriens. Le phénomène culturel de l'utilisation réelle de noms littéraires est étudié à partir du témoignage des documents d'archives, des comptes rendus de tournois et autres jeux courtois ainsi que des sceaux.

Dans la deuxième section («Ecritures en mutation»), l'étude de Mireille DEMAULES (Le 'Cycle de la gageure au Xv siècle: l'exemple français et l'exemple italien, pp. 85-99) porte sur le corpus de textes que G. Paris désigna sous l'appellation de 'cycle de la gageure', et tout particulièrement sur la mise en prose du Roman de la Violette ainsi que sur la nouvelle intitulée Justa Victoria, composée par l'humaniste italien Felice Feliciano; l'A. montre les transformations subies par le motif commun dans deux contextes culturels différents, sur le plan narratif et esthétique.

7 Maciej ABRAmowicz (Le remaniement de 'La Lille du comte de Ponthieu' ou l'écriture historiographique au $X v^{e}$ siècle, pp. 101-107) analyse succinctement la réécriture de ce texte telle qu'elle figure dans le Roman de Jehan d'Avesnes.

8 Maria colombo timelli (L'Erec' en prose, ou les traces de l'implication du lecteur dans un roman $d u$ xV siècle, pp. 117-131) étudie les interventions de l'instance narrative dans les deux témoins de la mise en prose d'Erec et Enide de Chrétien de Troyes; les remanieurs du manuscrit B (Bruxelles, B.R. 7235) et P (Paris, BnF fr. 363) divergent beaucoup sur ce point, mais l'analyse des rares passages de $B$ dans lesquels le narrateur prend la parole, ainsi que des autres manifestations indirectes du locuteur, montre tout l'intérêt de ce témoin, ainsi que la fonction des formules analysées, qui vont bien au-delà du simple cliché.

9 La section suivante a pour titre «Dons et débats»; Friedrich WOLFZETTEL (La poésie comme cadeau ou le goût de la lectrice vers la fin du Moyen Âge, suivi de Quelques réflexions sur la lyrique française du Moyen Age tardif: une poésie en contexte, pp. 133-156) fournit deux contributions complémentaires; dans la première, consacrée à l'Espinette Amoureuse de Froissart, l'A. analyse les trois étapes, toutes placées sous le signe de la lecture, conduisant l'héroïne de l'enfance à l'âge adulte et notamment l'introduisant à l'expérience d'amour; plus généralement, l'A. se penche sur les échanges poétiques entre les amants protagonistes de ce 'dit', en établissant un parallèle avec le Voir Dit de Machaut; dans la conclusion, la réflexion s'élargit au domaine de la poésie amoureuse pour définir les spécificités de la production française par rapport à d'autres littératures nationales.

10 David F. HULT (Lecture et relecture d'une affaire amoureuse: les réponses à la 'Belle Dame sans mercy', pp. 157-169) étudie les textes suscités par le débat sur la Belle Dame sans mercy, autrefois publiés par A. Piaget, en les mettant en relation avec l'importance croissante de la lecture individuelle et de l'écriture dans la période concernée, mais aussi avec la querelle du Roman de la Rose.

11 La dernière section est consacrée aux Bibliothèques et s'ouvre sur la contribution de Danielle QUÉRUEL (Du mécénat au plaisir de lire: l'exemple de quelques seigneurs bourguignons 
et en particulier de Louis de la Gruthuyse, pp. 197-211) qui, après avoir analysé quelques évocations littéraires de scènes de lecture dans la production bourguignonne, explore la riche collection privée de Louis de la Gruthuyse, homme politique de premier plan mais aussi bibliophile et mécène.

Helena KOGEN (Les goûts littéraires de la famille de Laval: constitution d'une bibliothèque familiale, pp. 213-223) prolonge cette réflexion dans le milieu angevin; après avoir relevé l'exiguïté de la documentation sur le sujet, elle dresse une liste des manuscrits ayant appartenu à la famille de Laval, en montrant quels étaient les centres d'intérêt autour desquels la collection se constitua.

Joëlle Ducos (Goût des sciences et écriture du savoir à la cour de Charles V, pp. 225-243) s'interroge sur les raisons qui poussèrent le roi Charles $V$ à commander des traductions françaises d'ouvrages scientifiques et analyse la fonction que ces 'mises en roman' jouèrent par rapport à la production contemporaine en latin, plus novatrice en termes de savoir scientifique.

14 Le travail de Claudia RABEL ('L'estude d'un tres noble seigneur garny a planté de pluiseurs beaulx livres'. L'iconographie des bibliothèques médiévales dans les manuscrits enluminés, pp. 245-277) veut être un premier défrichement du champ relativement inexploré de l'iconographie médiévale des bibliothèques; en se fondant sur un corpus de manuscrits enluminés s'étendant du Roman de Troie de Benoît de Sainte-Maure au Debat de la vraie noblesse de Miélot, en passant, entre autres, par la Bible historiale, quelques œuvres italiennes du Trecento et du Quattrocento, les Belles Heures de Jean de Berry, elle examine les différentes représentations de l'univers du livre.

La dernière section («Vers l'aval») comprend l'étude de Danielle BOHLER (Le lecteur dans le projet du livre: le roman chevaleresque et son prologue, du manuscrit aux imprimés, pp. 293-305), consacrée aux prologues de romans chevaleresques du milieu du $\mathrm{xv}^{\mathrm{e}}$ siècle, tant manuscrits qu'imprimés, dans lesquels on met en scène le topos du lecteur relatant sa rencontre avec un texte retrouvé.

Annie-France GARRus (Pierre Durand, lecteur de 'Guillaume de Palerne', pp. 307-312) analyse le dérimage du roman de Guillaume de Palerne réalisé vers le milieu du $\mathrm{xvI}^{\mathrm{e}}$ siècle par Pierre Durand et sa diffusion jusqu'au XVII ${ }^{\mathrm{e}}$ siècle.

Isabelle DIU ('Mundus insanit in libros sacros': le goût du lecteur comme justification de la stratégie éditoriale d'Erasme, pp. 313-324) s'intéresse au projet éditorial conçu par Erasme en collaboration avec l'éditeur Johann Froben pour la publication du corpus des auteurs de l'Antiquité chrétienne, en s'interrogeant surtout sur le public auquel les textes étaient destinés. 